\title{
La recepción de la música juvenil en Chile en los años 60: ¿americanización de la juventud?
}

\author{
Reception of youth Music in Chile in the sixties: \\ Americanization of the Young?
}

\author{
por \\ Silvia Lamadrid Álvarez \\ Facultad de Ciencias Sociales, Departamento de Sociología, \\ Universidad de Chile, Chile. \\ silamadr@u.uchile.cl \\ Andrea Baeza Reyes \\ Facultad de Ciencias Sociales, Departamento de Sociología, \\ Universidad de Chile, Chile. \\ andreaa.baeza@gmail.com
}

\begin{abstract}
El presente estudio analiza la música popular dirigida a jóvenes en Chile en los años sesenta. En una década marcada por los cambios y demandas de transformación social, las juventudes chilenas se articulan como actores sociales, y son incorporadas como consumidoras al mercado desde las industrias culturales. Desde una mirada crítica hacia las interpretaciones acerca de la apropiación musical en Chile, y siguiendo un enfoque cuantitativo, revisamos los rankings de las canciones más escuchadas por jóvenes entre 1961 y 1970 en las radios chilenas. Los resultados muestran cómo la música popular juvenil refleja la condición de una sociedad dependiente, abierta a influencias internacionales. Pero también, cómo la sociedad de la época tamiza la recepción de los nuevos géneros desde sus gustos y tradiciones, ya constituidos como mestizos. Ello permite sostener que las escuchas dirigidas a jóvenes en la segunda mitad de siglo XX corresponden a una hibridación compleja de géneros, en cuya construcción de identidades se entrelazan elementos modernos y tradicionales.
\end{abstract}

Palabras claves: música juvenil, años sesenta, gusto musical, hibridación, Chile.

This article analyses popular music addressed to young people in Chile in the sixties. In a decade characterized by changes and demands for social transformation, young people are important social actors who are incorporated as market consumers by cultural industries. From a critical perspective on interpretations about musical appropriation in Chile, and following a quantitative approach, we study the rankings of the most popular songs listened by youth between 1961 and 1970 on Chilean radios. Results show how popular music for youth reflects the condition of a

1 Este trabajo es financiado por el Programa de Apoyo a la Productividad Académica, PROA VID 2014; Universidad de Chile. (Academic Productivity Support Program, PROA VID 2014; University of Chile). 
dependent society, open to international influences, but also how young people of the time sieves the reception of new styles according to musical tastes and traditions, fully constituted as hybrid. This study argues that the musical preferences by youth in the second middle of twenty century are a complex hybridization of musical genres, which have constructed identities that interlaces modern and traditional elements.

Keywords: youth music, the sixties, taste in music, hybridization, Chile.

\section{INTRODUCCIÓN}

Este artículo describe y analiza la constitución del gusto juvenil en el campo de la música popular en Chile durante la década de los sesenta. Esta es parte de la cultura de masas "modernizante, mediatizada y masiva" que se consolida en este período, "entrelazada con la industria y la tecnología"2 y está marcada por el desarrollo tecnológico de los medios de comunicación y de los instrumentos musicales. En América Latina, la cultura de masas está signada por el enorme peso de la industria estadounidense del entretenimiento, pero también por la industria europea, sobre todo la italiana y española, facilitadas por el idioma y una larga historia de influencia ${ }^{3}$. La música popular comercial se nutre de múltiples fuentes en una relación de recepción-apropiación-reelaboración, y mediante ella, se construyen sentidos para millones de auditores y auditoras. El interés por estudiar la música popular estriba, entre otros, en su importancia en la construcción de identidades ${ }^{4}$, más aún para una generación emergente y que protagonizaría eventos relevantes para la historia de Chile en unos años más.

El estudio de la música popular es reciente -a partir de la segunda mitad del siglo pasado- cuya tradición proveniente del hemisferio norte tiende a omitir las relaciones con campos de asociación extramusical, al focalizarse en aquello que se escuchaba por sobre lo que se leía ${ }^{5}$. En América Latina, este campo se consagra en los años noventa, con investigaciones que abordan los cambios musicales en distintas regiones producto de las transformaciones tecnológicas. No obstante, el estudio de la música popular juvenil desde el enfoque sociocultural es reducido. Ante ello, proponemos vincular la música con factores sociales dinámicos de la época, para poner de relieve la complejidad de este fenómeno musical.

Si bien la irrupción del rock and roll, como espacio representativo de la cultura juvenil en Estados Unidos, se inició en 1955 y se exportó rápidamente al resto del mundo occidental, es en los años sesenta en que se consolida un mercado destinado a la juventud, instalando la música como señal de identidad de este grupo etario y construyendo al auditor juvenil como protagonista. Los años sesenta corresponden a un período de cambios sociales y políticos en que los jóvenes fueron un actor social importante, desafiantes del orden tradicional en diversos planos, no solamente el político, sino también en el de los géneros y las generaciones, especialmente en el control de la sexualidad. Más precisamente,

\footnotetext{
2 González, Ohlsen y Rolle 2009: 25.

3 González 2015.

4 Bennet 2000; Hormigos y Cabello 2004; González 2011.

5 González 2001.
} 
existe una modernización de la esfera simbólica y un nuevo trato del cuerpo, la sexualidad y los placeres ${ }^{6}$.

En este marco, se busca comprender los cambios en las tendencias en la industria y en el gusto musical de jóvenes en el período, como expresión de la constitución de la música destinada a este grupo social, cuestionando la noción de sentido común que supone una asimilación unidireccional de la influencia estadounidense o americanización, desde los recientes estudios culturales y musicológicos que han develado a lo popular como un espacio de hibridación. Finalmente, se aporta evidencia para resolver cuál fue la forma específica en que se dio el proceso de apropiación de la música juvenil en Chile.

\section{ANTECEDENTES}

\subsection{Lo popular y la música popular}

Lo popular es un concepto polisémico que puede referirse a: i) el espacio de la tradición en oposición a la modernidad; ii) un sujeto histórico; iii) la legitimación de un orden político o iv) lo masivo. Para efectos analíticos adscribimos a esto último, porque apuntamos al "espacio mediado por la alta penetración y recepción en las audiencias de las industrias culturales, en un contexto crecientemente urbano y modernizado" 7 . De este modo, lo popular será la aceptación pública o preferencia de los consumidores de las industrias y se inscribe tanto en la cultura como en el mercado.

Respecto de los gustos culturales expresados en prácticas y preferencias, Bourdieu sostiene que están estrechamente vinculados con los niveles educacionales y el origen social de los individuos y grupos. Solo quienes poseen los códigos para dar sentido e interés a las obras de arte están en condiciones de reconocer su lógica interna y, por tanto, comprenderlas y gustarlas. Con ello se opone a la ideología carismática que ve en los gustos culturales un don natural que habilita para el deleite ante una obra de arte ${ }^{8}$.

Los gustos singulares pueden agruparse en tres universos con gran correspondencia, pero no determinación con las clases sociales: el gusto "legítimo" por las obras mayores, el gusto "medio" por las obras menores de las artes mayores y finalmente, el gusto "popular" por la elección de obras de la música "ligera” o de música culta desvalorizada por la divulgación ${ }^{9}$. Bourdieu subraya el carácter particularmente vinculado al origen y pertenencia de clases de los gustos en música, ya que la adquisición de las disposiciones para alcanzar el gusto por las obras más exigentes tiene dificultades especiales ${ }^{10}$. La "estética" popular es una estética dominada, obligada a redefinirse permanentemente en relación con las estéticas

\footnotetext{
6 Hobsbawm 1999; González 2011.

7 Palominos 2011: 6.

8 Bourdieu 2003/2010: 231-234.

9 Bourdieu 1979/1998: 14.

10 Bourdieu 1979/1998: 16.
} 
dominantes, percibida hasta por sus propios defensores desde esa perspectiva que las reduce y desvaloriza, viéndose forzadas a la degradación. Al interior de las artes populares se da nuevamente una jerarquía interna entre quienes se acercan más a la estética dominante y quienes se apartan más de ella.

Para nuestro caso de estudio, adoptamos la propuesta de Palominos quien define lo popular como un espacio topográfico ${ }^{11}$ y tropográfico ${ }^{12}$ en "constante oposición, conflicto y negociación con la posición dominante”. Pero este espacio "no es completamente cooptado por una determinada clase social, aunque en él circulan e instalan clases que comparten una orientación de disputa y negociación con los centros de poder" 13 . Haciendo convergentes ambos enfoques, lo popular se trata de un espacio privilegiado para la ocurrencia del mestizaje cultural, generando movilizaciones, contactos e intercambios que desplazan las limitaciones que distinguen de la élite. En este sentido, lo popular también es "una construcción producida a partir de los medios de comunicación, logrando homogeneizar comportamientos, valores, gustos, patrones de consumo y expectativas de vida modernos y comunes para gran parte de la población"14.

La música, dentro del espacio relacional de lo popular, concierne a la vida social donde se asienta la producción y el consumo cultural de masas. En ella confluyen las decisiones de los músicos (quienes escriben letras y melodías), las discográficas y los programadores de radio (quienes deciden qué debe tocarse y qué debe emitirse) y los consumidores (quienes concentran su atención en determinados géneros) ${ }^{15}$. La música popular se considera una "interacción social más que un discurso preexistente", donde "las respuestas de los receptores van también configurando el discurso cancionístico que se va adaptando progresiva y sistemáticamente a las expectativas receptivas de comunidades lingüísticas que la consumen"16.

Frith ${ }^{17}$ establece que este fenómeno social es relevante por las múltiples funciones sociales que contempla, en cuanto a la identidad, la administración de la relación entre la vida emocional pública y privada, y porque permite dar forma a la memoria colectiva y organizar el sentido del tiempo. Por ello, es clave para la representación individual y colectiva en un determinado contexto: permite expresar y darle forma a nuestras identidades socialmente construidas, a la vez que "en al menos los últimos cincuenta años la música popular ha constituido una vía fundamental para aprender a entendernos como sujetos históricos, con identidad étnica, de clase, de género" 18 . Adicionalmente, la música popular constituye "uno de estos ámbitos de creación mixta, que combina la producción lingüística con

11 Donde habitan y circulan diversos agentes y repertorios simbólicos.

12 Donde se dan procesos de intercambios, mezclas, mestizajes e hibridaciones entre agentes y símbolos.

13 Palominos 2011: 7.

14 Santa Cruz y Santa Cruz, 2005 citado en Palominos 2011: 6.

15 Frith 2001.

16 Muñoz-Hidalgo 2007: 105.

172001.

18 Frith 2001: 434. 
fuertes componentes identitarios típicos de las creaciones colectivas" y es "un subgénero artístico que en todo el continente ha dado muestras de una fecundidad pasmosa y un empuje tan vigoroso que han hecho de la canción latinoamericana una de las más importantes contribuciones artísticas y culturales de América a la civilización mundial" ${ }^{19}$. Su importancia estriba en la amalgama de contenidos y géneros musicales que comprende dentro de una circulación profusa, la que es imposible comprender sin hacer alusión a las fuerzas de producción y difusión cambiantes que la van plasmando, así como a su ubicación histórica en contextos más amplios de significación social.

Sobre esto último, Palominos advierte que dentro de la larga tradición de estudios culturales realizados desde los años ochenta acerca de la producción y consumo cultural en los contextos globalizadores contemporáneos, una parte importante ha privilegiado la interpretación de la música popular como un espacio de denuncia de poder, en vez de un soporte del mismo. No toda música popular necesariamente se erige como antihegemónica, pero tampoco está exenta de tensiones con la hegemonía cultural, mediante los "procesos de mestizaje e hibridación [que] juegan un rol de importancia en tanto estrategias de los agentes involucrados en el campo cultural" 20 .

\subsection{Los géneros musicales}

Los géneros en la música popular han sido abordados por distintos autores, Fabbri, Frith, Hamm, y en nuestro continente Orozco, Santa María y Janotti ${ }^{21}$, quienes coinciden mayoritariamente en incorporar además de los elementos musicales, otros, como la performance, la naturaleza cultural de la música y el contexto político, económico y social para su estudio. Con ello se incluye en su clasificación además de las cualidades intrínsecas del lenguaje musical, el cómo ella es usada ${ }^{22}$. Guerrero también revisa las dificultades para cerrar los límites de los géneros, tanto en términos teóricos de construcción de categorías inclusivas y exclusivas como en términos empíricos, ya que los géneros están en permanente cambio por la intervención de los sujetos participantes en su creación, difusión y escucha ${ }^{23}$.

En América Latina la definición de los géneros musicales se ha ligado a la identidad nacional, combinando en ello esfuerzos gubernamentales, de movimientos intelectuales o políticos y de la industria musical ${ }^{24}$. En este proceso, los géneros han sido resignificados y reclasificados continuamente, además de integrar nuevas corrientes musicales.

19 Muñoz-Hidalgo 2007: 102.

20 Palominos 2011:5.

21 Citados por Guerrero 2012.

22 Guerrero 2012.

23 Guerrero 2012: 19-20.

24 Santamaría 2005. 


\subsection{Nuevos géneros musicales: el rock and roll}

Existen numerosas investigaciones sobre los cambios en los gustos musicales ocurridos entre la juventud en América Latina y Europa en el período. Estas recalcan la tensión entre la música proveniente de Estados Unidos, el rock and roll, acogida generalmente por los jóvenes, el rechazo inicial por parte del mundo adulto, incluso de la industria musical nacional, y cómo se absorbieron estas nuevas influencias ${ }^{25}$. Juan Pablo González documenta la rápida recepción que tuvo este género, con el apoyo del cine ${ }^{26}$. A partir de 1956 los espectáculos musicales y los shows radiales incorporarán orquestas de rock y competencias de baile. Las y los jóvenes chilenos bailaban el nuevo ritmo "en los cines, las carpas playeras, las kermés escolares, los auditorios radiales, y las fiestas, malones y bailoteos" 27 , generando escándalo en los adultos. Para González, este impacto corporal fue clave en la penetración del rock and roll en la cultura chilena, constituyendo una señal de identidad para una rebeldía juvenil que recién se empezaba a expresar.

El proceso de rechazo adulto y recepción juvenil ante el rock and roll, y la consiguiente reacción de los controladores del espectáculo para suavizar y adaptar la rebeldía roquera ocurrió en Estados Unidos, donde los cantantes negros fueron desplazados y los intérpretes sometidos a un riguroso tratamiento para limitar sus excesos, promoviendo a aquellos con performances más conformistas ${ }^{28}$. En la Europa de los 50, Kouvarou ${ }^{29}$ analiza la recepción del rock and roll en Alemania, Grecia, Italia y Francia, y cómo el rechazo y la asimilación de la inevitable ola de música juvenil estadounidense tuvo sus especificidades. Sin embargo, en estos cuatro países la tendencia fue la misma: el rock fue asimilado por la industria y reelaborado con los matices nacionales en una versión suavizada, integrada a una movilización del conjunto de la industria y los medios, intentando la construcción de una cultura juvenil funcional a sus intereses y controlando sus elementos más rupturistas.

En la España franquista, la dictadura estaba abierta a las influencias norteamericanas pero ejercía un férreo control sobre las versiones nacionales, que cantaban en castellano canciones rocanroleras edulcoradas y transformadas ${ }^{30}$. Y si en general las versiones nacionales de los ídolos rocanroleros eran "buenos chicos", en oposición a los salvajes rocanroleros estadounidenses ${ }^{31}$, en el caso

25 Ordovás 1986; Alabarces 1993; Giménez 1999; Polimeni 2001; González 2006; González 2011; Otaola 2012; Kouvarou 2015; Pujol 2015.

26 La popularidad alcanzada en Estados Unidos por Rock Around the Clock, de Bill Haley \& His Comets, incluida en los créditos de la película Blackboard Jungle (Semilla de maldad, 1955), constituye una de las primeras noticias que se difundieron en Chile en relación con la existencia del rock and roll (González 2011: 22).

27 2006: 20-22.

28 González 2006: 22.

292015.

30 Otaola 2012.

31 Kouvarou 2015. 
español los "chicos ye-ye"32 eran aún más conformistas, por la obsesión moralista de la dictadura. Al igual que en América Latina, a fines de los sesenta el espacio de crítica y rebeldía social y cultural que ocupó el rock en otras naciones, en el país ibérico lo llenó el movimiento de la Nueva Canción ${ }^{33}$.

En la América hispanoparlante, México jugó un papel mediador en la difusión del rock and roll, porque su enorme industria del entretenimiento ya tenía fuerte influencia en Sudamérica. Allí la "cultura juvenil" ha sido poco investigada, existiendo escasos estudios acerca de música que estén concentrados en la historia del rock $k^{34}$, y en estos los años sesenta son poco importantes ${ }^{35}$. En este país el Estado postrevolucionario impulsó desde los años veinte una transformación cultural con notorio sentido nacionalista, que utilizó tanto los nuevos medios de comunicación como expresiones artísticas emergentes para crear la ilusión de una nación mestiza con su cultura propia. Con ella se fue instalando la figura del mariachi y el charro como el estereotipo del mexicano, convertida en un producto mediático popular en México y la mayor parte de América Latina ${ }^{36}$. En contraposición, la música rock aparecía al principio como ajena y elitista, y tuvo la oposición de la industria y los sindicatos. La tensión entre el rock estadounidense y el nacionalismo produjo una primera versión del rock en castellano, carente de elementos críticos, que tuvo gran difusión en toda América Latina.

En Argentina la llegada de la música juvenil anglosajona se insertó en un contexto similar, ya que el peronismo había favorecido el desarrollo de la música de proyección folklórica popularizada en los años treinta y cuarenta ${ }^{37}$. Posteriormente en los cincuenta fundió elementos tradicionales con estéticas cultas, resultando en el "nuevo folklore" 38 cuya popularidad se afirmó teniendo como focos grandes festivales, y se extendió por América Latina ${ }^{39}$. Pese a ello, Argentina fue el país sudamericano que mejor recibió el rock, y se ha desplegado un gran interés académico y periodístico respecto de la asimilación de este género, lo que derivó en la emergencia del llamado rock nacional, producto híbrido entre la influencia anglo y su reelaboración como expresión juvenil contracultural ${ }^{40}$.

32 Descripción del Dúo Dinámico, el conjunto ye-ye más popular: "La imagen de los dos chicos jóvenes, guapos, bien vestidos, simpáticos y españoles se hizo familiar entre la juventud. Llevaban el pelo bien cortado y peinado como los cantantes norteamericanos y fueron los primeros en utilizar el atuendo como seña de identidad. La ropa que más les caracterizó fue el chaleco rojo sin mangas con cuello de pico. Siguieron otros modelos con mangas o sin ellas y otros colores, pero siempre el jersey de pico" (Otaola 2012).

33 Polimeni 2001.

34 Valdéz 2001; Malacara 2001; Estrada 2008.

35 Giménez 1999: 124.

36 Vega 2011; Garibaldo y Bahena 2015.

37 Vila 1987.

38 Los Chalchaleros, Los Fronterizos, Los Cantores de Quilla Huasi, Los Cantores de Salavina, Los 4 de Córdoba (Gutiérrez 2005).

39 Vila 1987.

40 Pujol 2015; Alabarces 1993. 


\title{
2.4. Los cambios en la música y en las generaciones en Chile
}

En Chile, el pánico moral en el mundo adulto ante el desembarco del rock and roll con todas sus expresiones mediáticas y objetos asociados, radios, tocadiscos, vestimenta, entre otros, está ejemplificado en el caso de abril de 1959 de Carlos Boassi Valdebenito, el Carloto $^{41}$, y la construcción en los medios de comunicación de los "coléricos" como representación de una juventud en peligro de descarriarse por la influencia estadounidense. En el país hubo una intensa preocupación por normalizar a los "jóvenes disfuncionales o desviados" 42.

La reacción de quienes lideraban la naciente industria de la cultura de masas también está documentada por González y colaboradores, respecto del comentario del productor musical Camilo Fernández, criticando la perniciosa influencia de Elvis Presley, pero afirmando el potencial de la juventud chilena de permanecer fiel a los "valores humanos" si se promovía entre ellos la moda del buen comportamiento ${ }^{43}$. Eso hará efectivamente Fernández como gestor de la Nueva Ola, y lo harán también las nuevas revistas juveniles ligadas a la promoción de los ídolos juveniles de la canción. Estas se enfocaban en ampliar la experiencia de los jóvenes y explicitaban su interés en dar expresión a un sector social que no la había tenido, y que estaba siendo criticado desde el mundo adulto:

\begin{abstract}
"queremos mostrar a los adultos que la juventud no es una etapa pasajera, sino un estado de ánimo, activo y pleno de energías; que el twist y el 'surf' son expresiones de vitalidad; que el cantante romántico está simplemente poniendo en música y palabras los deseos de ternura y compañerismo de muchos jóvenes, y que la juventud, en toda época, ha sido como debe ser: una respuesta diferente ante los desafíos de una época que es también diferente en cada generación" 44 .
\end{abstract}

La absorción del rock and roll en la música popular juvenil en Chile también fue temprana y adquirió patrones similares a las naciones mencionadas. Como lo indica Lamadrid ${ }^{45}$, durante este periodo existieron disposiciones de apertura, y otras renuentes a los cambios. Serán estas últimas, tanto desde el discurso como desde la industria y la práctica misma del baile, las que intentarán la domesticación del rock and roll, lograda momentáneamente con la Nueva Ola.

El vínculo entre padres e hijos jóvenes hasta fines de la década de los cincuenta se vivía bajo una clara "hegemonía adulta" 46 . En ese momento se abre espacio a la irrupción de los jóvenes como grupo social, atraídos por las promesas de movilidad social de la modernidad, quienes encontraron que las puertas no estaban abiertas

41 Joven de clase acomodada, acusado de la muerte de su polola, fue convertido por los medios en ejemplo de los nuevos grupos de jóvenes que adoptaban los modos rocanroleros (González 2011).

42 González 2011: 19.

43 González, Ohlsen y Rolle 2009: 624.

44 Rincón Juvenil $\mathrm{N}^{\mathrm{o}} 1$ (16 de diciembre de 1964), Editorial, p. 2.

452014

46 Salazar y Pinto 2002. 
para todos. Serán los estudiantes universitarios ${ }^{47}$ de sectores medios y altos, en parte por la expansión del sistema educativo ${ }^{48}$, quienes se convierten en "el gran actor político emergente (...remitiendo) a cambios sociales estructurales" 49 . Además de su importancia en política en esta década, las juventudes ${ }^{50}$ vinieron a ser nuevos nichos para la industria cultural de la época, entre ellas, la de la música.

"La música juvenil es socialmente importante no porque refleje la experiencia de los jóvenes, sino porque define para nosotros lo que es la juventud" 51 . Este fenómeno social íntimo y público a la vez, permitió materializar opciones de atribución de sentido en la afirmación de identidad para esta nueva generación emergente. Ello ha de vincularse con las transformaciones en las fuerzas de producción musical, siendo clave el fenómeno de la mediatización, que cambió "radicalmente el modo que hemos practicado y usado la música en el siglo XX"52. Ciertos cambios en las tecnologías ${ }^{53}$ de la música conciernen a los usos espaciales y generacionales. Inicialmente, cuando la radio y la victrol ${ }^{54}$ tenían un formato pesado y voluminoso, estaban situadas en el living $^{55}$ de la casa para que la música fuera escuchada por toda la familia. Con la aparición de la más pequeña radio de velador y sobre todo la radio a transistores y la simplificación del tocadiscos en su versión portátil, la experiencia de escuchar música se pudo trasladar desde el living a la privacidad de los dormitorios de los adolescentes. Así se articuló el desplazamiento de la música "del salón al living" 56 y del living al "cuarto propio" de jóvenes ${ }^{57}$.

Por su parte, fue fundamental la confluencia de otros medios de comunicación para potenciar ciertas escuchas musicales desde la industria. El cine, la prensa y la televisión colaboraron en esta apropiación juvenil de la música, difundiendo a los intérpretes y sus canciones, con su corporalidad y performance. En los sesenta en Chile aparecieron en los escenarios "solistas y grupos de jóvenes interpretando

47 El movimiento estudiantil tuvo una creciente presencia en la vida nacional. Según los historiadores Salazar y Pinto (2002), en la segunda mitad de la década, la generación universitaria es la que ha tenido mayor protagonismo en la historia de Chile, usando múltiples espacios de lucha como son la calle, la fábrica, el fundo y la plaza, y estrategias como las ocupaciones ilegales o tomas.

48 En 1950, la cobertura educacional de la población de 0 a 24 años de edad era del 26,5\%, y en 1964 pasó a 35,8\% (Lamadrid, 2014).

49 Lamadrid 2014: 79.

50 Hablamos de juventudes, en contra de las acepciones más clásicas que reducen a un grupo social homogéneo, desconsiderando las especificidades y el contexto acerca de sus condiciones sociales y materiales (Martín 1998). Así, bajo una matriz adultocéntrica y patriarcal, se invisibilizan las diferencias y distinciones de jóvenes (Duarte 2000: 67).

51 Solís 2010: 9.

52 González 2001: 39.

53 Nos referimos a los discos gramofónicos del siglo XIX, y al uso de la radio a partir de los años 20, y con ella, la creación de un nuevo tipo de público, que participaba simultáneamente de un evento sin estar en el mismo lugar. Luego aparece el micrófono, artefacto que modifica las maneras de interpretación antes operáticas, haciéndolas más informales e íntimas con la audiencia (González, Ohlsen y Rolle 2009).

54 Especie de todadiscos llamado así por ser propiedad de RCA Victor.

55 Living-room, sala o cuarto de estar.

56 González, Ohlsen y Rolle 2009.

57 Brabazon 1993. 
canciones principalmente en inglés, editando miles de discos, apareciendo en portadas de revistas, realizando giras y dando la pauta de la programación radial" 58. Es así como la experiencia individual de cada joven se hacía en el contexto de una cultura de masas, la de los ídolos de la canción, con los que era posible imaginar un vínculo personal, precisamente a partir de estas tecnologías.

En este contexto, no cabe duda que la radio y su paulatina masificación "ayudó a que los músicos que solo se daban a conocer en escenarios cerrados podían llegar a los hogares de miles de personas a través de la transmisión de espectáculos en vivo" 59 . La radiodifusión elevó a dimensiones insospechadas la popularización de la música, que ahora podía llegar a millones de auditores cómodamente instalados en la privacidad de su hogar. A medida que avanza la década, son los discos y su radiodifusión y no los conciertos lo que definen mejor el sonido de la música po$\operatorname{pular}^{60}$. Con ello, la masificación de la escucha por medio de los discos fue "dando así la pauta de un nuevo consumo" 61 que en los jóvenes se articuló también con resistencias y negociaciones.

\section{MARCO METODOLÓGICO}

Esta investigación utiliza un enfoque cuantitativo, basado en la estrategia de asignación de números a las magnitudes, grados o tipos identificados en el objeto de estudio delimitado conceptualmente de manera deductiva y utiliza procedimientos estadísticos para resumir, manipular y asociar dichos números ${ }^{62}$. El carácter del estudio fue descriptivo-exploratorio ${ }^{63}$, cuya directriz consistió en definir y caracterizar la música juvenil a la luz de la industria musical y mediática. El alcance fue transversal, sin repeticiones en cuanto al levantamiento de información, realizado entre diciembre de 2014 y abril de 2015. Este consistió en la construcción de una base de datos en el software estadístico IBM SPSS v.17, donde las fuentes fueron los rankings de música juvenil entre 1961 y 1970, con las 10 canciones mayormente escuchadas en las radios, publicados semanalmente por la revista Ritmo de la Juventud. Los casos faltantes fueron completados con las revistas Ecran, Radiomanía y Superventas de Billboard.

Ya señalamos las dificultades para definir los géneros musicales en música popular. Considerando, además, que las canciones de los sesenta corresponden a un período de gran hibridación, hemos tratado de construir categorías amplias y que incorporen tanto los aspectos musicales como sociales y culturales, especialmente la performance de los intérpretes, que en estos casos es particularmente significativa. A saber, muchos casos de cantantes del movimiento de la Nueva Ola interpretan canciones de géneros tradicionales, pero con performance propia del género rock o

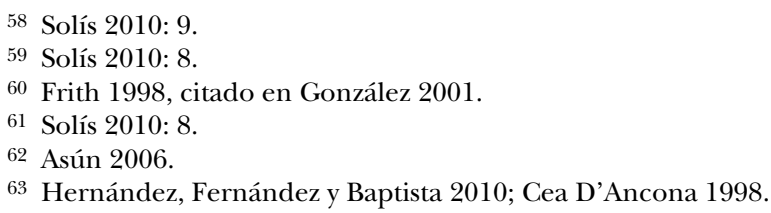


pop que está emergiendo en el período ${ }^{64}$. En función de ello, y para los fines de este trabajo, además de los géneros ya aceptados para la música popular ${ }^{65}$, como el bolero, usaremos las siguientes denominaciones:

- Canción melódica: incluye la también llamada canción ligera, que recoge las tradiciones norteamericanas, de la canción francesa, italiana, del cuplé español, del bolero latinoamericano y otras. Para recoger esas diferentes tradiciones, los hemos agrupado en canción melódica europea, latinoamericana y norteamericana. Hemos incluido a los cantautores de las Nuevas Canciones, o trova, en un grupo específico.

- Rock: en este grupo incluimos a las primeras expresiones del rock and roll norteamericano e inglés, a sus cultores latinoamericanos (muchos de ellos identificados con Nuevas Olas), y luego al rock clásico que emerge tras la aparición de The Beatles, y a los intérpretes latinoamericanos que acogen esta nueva propuesta.

- Neofolklore: incluye a los intérpretes que reelaboran géneros folklóricos latinoamericanos, con nuevos instrumentos y armonías.

- Música tropical: comprende música originaria del Caribe y norte de Sudamérica, mezcla de ritmos de origen africano, fusionadas con el folklore y ritmos latinoamericanos.

\section{RESULTADOS E INTERPRETACIONES}

Las canciones incluidas en los rankings entre 1961 y 1970 reflejan una mezcla compleja de géneros, donde se entrelazan elementos modernos y tradicionales. La música refleja una sociedad dependiente, abierta a influencias internacionales, pero que tamiza la recepción de los nuevos géneros desde sus gustos y tradiciones (ya constituidos como mestizos) ${ }^{66}$. Las listas de éxitos contienen lo que la industria del disco, la radio, del espectáculo y los medios están constituyendo como "música juvenil".

Dentro de esta sistematización de la administración de la escucha juvenil, el género de la canción melódica es el de mayor difusión, en sus diversos subgéneros $(61,4 \%)$, siendo el de mayor presencia el latinoamericano $(34,9 \%)$, seguido del europeo $(15,9 \%)$. Comparativamente, las diversas expresiones del rock son minoritarias $(28,6 \%)$, pero juntos ocupan casi todo el rango (90\%); y dentro del género, el que tuvo mayor presencia fue el rock clásico anglo (12,6\%), signado por

64 Ejemplo de ello son la balada con rasgos de bolero Entre la arena y el mar, grabada por el cantante de rock and roll Peter Rock en 1963, el rock lento con rasgos de bolero Piensa grabado por los nuevaoleros Red Juniors en 1962 (González, Ohlsen y Rolle 2009: 524-525).

65 Pujol 2013.

66 Larraín 2004. 
la poderosa presencia de The Beatles. Los demás géneros presentan una frecuencia total inferior al 4\% (ver Gráfico 1).

\section{GRÁFICO 1 \\ GÉNERO MUSICAL DE LAS CANCIONES EN LOS RANKINGSJUVENILES}

$(\mathrm{N}: 4.261)$

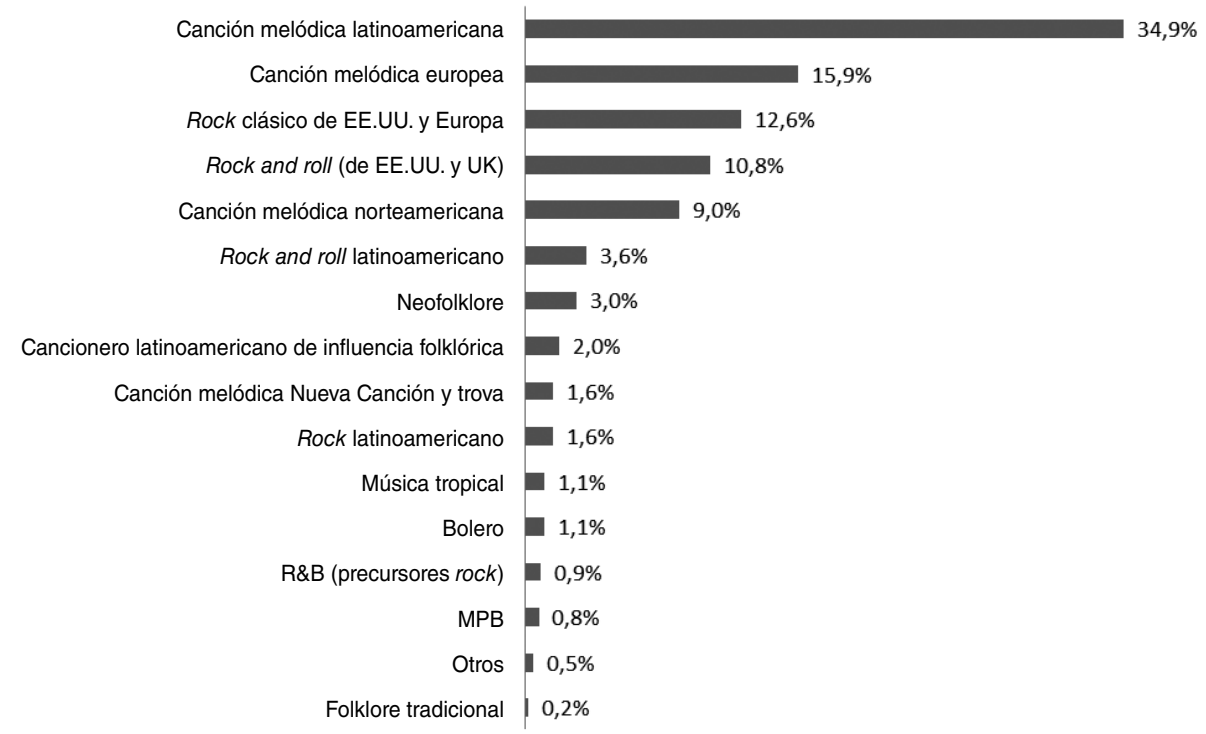

Fuente: Elaboración propia.

Para comprender mejor las decisiones que están tras la construcción de la noción de música juvenil, revisaremos primero los géneros que han quedado fuera de ese concepto, considerando aquellos escuchados en el país en la década previa y durante el período. Proponemos que fueron excluidos varios de los géneros tradicionales latinoamericanos por estar vinculados, primero, a los códigos de gusto musical adulto (la generación de los padres de los jóvenes de los sesenta), como es el caso del tango y el bolero, y segundo, aquellos gustos del mundo rural y popular, como la música tradicional mexicana, el vals peruano y el folklore chileno.

Entre la música popular difundida en Chile en la década de los cincuenta, el tango tuvo una enorme importancia como música bailable, pero ya tenía menor exposición hacia fines de los cincuenta, aunque contaba con un público fiel que lo bailaba y escuchaba. No tendrá presencia en las listas, con la excepción de su versión europea y en voz de Cecilia, cantante de la Nueva Ola chilena: el Tango de las rosas ${ }^{67}$. El bolero había tenido su máximo desarrollo comercial en

67 González, Ohlsen y Rolle 2009: 571. 
esa misma década, y contaba con reconocidos intérpretes nacionales con carrera internacional, como Lucho Gatica y Antonio Prieto ${ }^{68}$. Posiblemente por eso mismo tuvo algunas apariciones en los rankings, aunque muy minoritarias. La performance de los cantantes de tango y bolero tiene una formalidad propia del mundo adulto y un dramatismo en sus letras, que en la ruptura de las normas lleva a la tragedia, en cambio la música juvenil propone una transgresión desdramatizada de esas normas.

Considerando la música que tenía mayor presencia en la industria y en los medios en ese mismo período, es notoria la ausencia de la música tradicional mexicana: rancheras y corridos, que de acuerdo con González, Ohlsen y Rolle, gozaban de enorme popularidad en el público chileno no juvenil ${ }^{69}$. Este género había arraigado en el mundo rural nacional precisamente por su temática campesina, derivando incluso en su nacionalización, ya que fue recreada por intérpretes chilenos $^{70}$. En el conjunto de canciones registradas, ninguna corresponde a este género; los pocos intérpretes mexicanos son rocanroleros como Enrique Guzmán. En esta exclusión influye también que esta música era traída a la ciudad por los migrantes rurales, que se desempeñaban dentro de las posiciones más bajas en la escala ocupacional: trabajadoras domésticas, obreros de la construcción e incluso carabineros. La socióloga chilena Soledad Bianchi recuerda:

“...el dial era tan jerarquizado como la sociedad entera. Jamás en «Hoyl» (una casa de venta de discos), en el centro neurálgico del barrio alto, se oiría una ranchera, un corrido ni un vals peruano (si bien uno de Strauss podía acogerse con placer). Y en nuestras casas, de clases medias acomodadas, estas músicas que venían de la cocina o de las habitaciones de las empleadas domésticas, empezaban a gustarme..."71.

Hubo, entonces, una decisión de no incluir este género dentro del corpus de la música juvenil por su marca de clase, aun cuando vendían discos y tenían audiencia radial, pero esos programas no eran considerados entre los que aportaban información para los rankings juveniles.

La segunda exclusión notoria es el vals peruano, con algunas excepciones: el vals Amarraditos, en la versión de los intérpretes de neofolklore Los Cuatro Cuartos en junio de 1964 y Hoy se casa, interpretada por Luis Alberto Martínez, en mayo de 1963. Era un género que tenía enorme popularidad en Chile en ese período y sus principales intérpretes nacionales ${ }^{72}$ fueron grandes superventas del período, pero no tuvieron presencia en los rankings juveniles analizados.

68 González, Ohlsen y Rolle 2009.

69 El cine mexicano era la principal plataforma de esa música; también había intérpretes nacionales, como Guadalupe del Carmen, que en 1954 había vendido 175 mil ejemplares de su single Ofrenda. La audición de radio de más alta sintonía en Santiago era Cuando México canta (González, Ohlsen y Rolle 2009: 454).

70 Mularski 2015.

71 Bianchi 1987.

72 Lucho Oliva (Disco de Plata RCA en 1957), Lorenzo Valderrama, Palmenia Pizarro (Disco de Oro en 1964) y Rosamel Araya (González, Ohlsen y Rolle 2009: 458) 
En este caso, también opera la marcada identificación de esta música con las clases populares, sumado a una mayor evidencia del mestizaje en el fenotipo de sus intérpretes. Su invisibilización era una decisión de quienes controlaban los medios, como ha sido descrito respecto de Palmenia Pizarro por parte de la revista Ritmo de la Juventud ${ }^{73}$.

Otra exclusión importante es el folklore tradicional, a pesar que en los años 50 se había asentado su conceptualización y repertorio contando incluso con apoyo desde las universidades y de la industria musical ${ }^{74}$. Este género ingresará más tarde a la música juvenil en su versión más sofisticada y urbana, como neofolklore, incorporando elementos del emergente folklore argentino. Pero sus versiones tradicionales, profundamente ligadas al mundo rural, a las actividades agrícolas y ganaderas, son dejadas fuera del campo de lo juvenil. En resumen, este mundo juvenil se constituye como esencialmente urbano, blanco y de clase media. Los elementos folklóricos serán incorporados en versiones evidentemente urbanas, como el caso del neofolklore. Antes de exponer las corrientes principales de los géneros musicales que sí fueron incluidos, revisaremos dos géneros latinoamericanos que fueron aceptados como música juvenil: el neofolklore y la música tropical.

Aunque los géneros tradicionales latinoamericanos quedaron fuera, su reelaboración como neofolklore tanto argentino como chileno tuvo un breve pero importante período de presencia en los rankings en 1965 y 1966, precedido por una modesta presencia del cancionero latinoamericano entre 1961 y 1963, fundamentalmente canciones del folklore litoraleño argentino y paraguayo, interpretados por dos chilenos, Lorenzo Valderrama y Ginette Acevedo. Estas canciones no tenían la connotación campesina del folklore tradicional chileno, sino que remitían a experiencias rurales marcadas por el exotismo de climas cálidos y costumbres distintas. El nuevo folklore argentino masificado en los sesenta influyó en el neofolklore nacional, que adoptó de él instrumentos, armonías vocales y canciones que se apartaban de las tradiciones nacionales y convirtió a sus intérpretes en blanco de las críticas de los cultores folklóricos tradicionales. Los Cuatro Cuartos y otros conjuntos parecidos del neofolklore tenían una performance indiscutiblemente urbana y de clase media, incluso clase acomodada. A diferencia de ellos, el grupo que fundará hacia el final de la década la Nueva Canción chilena era de origen y aspecto más popular, varios de ellos profesores primarios y vinculados a los partidos de izquierda. Los únicos que entran al ranking son Patricio Manns y luego Julio Zegers, cuyo origen de clase y menor compromiso político lo hacían aceptable; Ángel e Isabel Parra aparecen versionando La Tropillita en compañía de Los de Las Condes, y la canción Gracias a la vida ingresa interpretada por Cecilia (no por su autora, Violeta Parra). Como Nueva Canción fueron excluidos por su evidente posición política en un país cada vez más polarizado y con la revista Ritmo más derechizada a medida que avanza la década.

73 Lamadrid 2014: 180.

74 González, Ohlsen y Rolle 2009: 311. 
El cierre urbano y de clase media blanqueada que señalábamos anteriormente hace más interesante la sobrevivencia de la música tropical (cumbia y otras) tal vez porque logra insertarse en el tono juguetón de la música juvenil, y con la música playera. En muchos países de América Latina la cumbia colombiana ha sido apropiada y folklorizada, incorporando rasgos particulares, siendo uno de los géneros bailables de mayor consumo, fundamentalmente entre los sectores populares, pero también entre las clases medias ${ }^{75}$. En Chile, este ritmo cadencioso y simple ha dado el espacio para expresar la corporalidad chilena, reprimida por las rígidas directrices gubernamentales que desde la República trataron de normar la sociabilidad y festividad popular, convirtiéndose en la música de la fiesta, tanto en el espacio público como en las celebraciones domésticas. Afirmándose además en letras sencillas, alegres y cotidianas, han sido apropiadas por el público nacional, que también las canta colectivamente en las celebraciones ${ }^{76}$.

Ahora expondremos los géneros musicales con mayor presencia a lo largo de la década y sus variaciones (ver Gráfico 2). Los géneros que se adecuan a los códigos de clase, etnia y localidad validados por la industria y los medios son los que encontramos en los rankings. La primera música juvenil es el rock and roll original, en su versión blanca. Para 1960 ya había pasado el primer período de rock and roll liderado por Elvis, pero seguían siendo cantantes juveniles norteamericanos los que dominaban el campo, en su versión más carente de elementos de crítica social (llamados pretty faces por su performance de chicos buenos). Música rítmica, bailable, que posiciona el cuerpo juvenil y sus expresiones eróticas en el espacio público decente, a diferencia del bolero y tango, que son expresiones marginalizadas y adultas. Al igual que en los países de habla no inglesa revisados, su absorción por la industria musical nacional ocurre entre la recepción juvenil y el rechazo adulto de esta música extranjera. La barrera del idioma produjo igual que en Argentina cierta elitización del rock, donde si bien el ritmo y la expresividad convocaban, había que traducirla a códigos más asequibles a la mayoría juvenil, si se la quería masificar.

El año 1961 se inicia con predominio del rock and roll en inglés (39\%) y de la canción melódica en inglés (mayoritariamente pretty faces) (31,9\%), que se mantienen al año siguiente con $47 \%$ y $16 \%$, respectivamente. En esos dos años la canción melódica latinoamericana tuvo apenas $10 \%$, principalmente cantantes de las Nuevas Olas de la región. En 1963 este es el grupo de mayor presencia (33\%) desplazando al rock and roll anglo (22\%) pero acompañado también de intérpretes latinoamericanos de rock and roll (19\%). 1964 es el año de mayor presencia de la canción melódica latinoamericana $(55 \%)$-que se mantendrá en el primer lugar hasta 1970-, la canción melódica europea registra $19 \%$ y existe una mínima presencia del rock (10\%) fundamentalmente gracias a la aparición de The Beatles. En 1965 y 1966, aunque el rock clásico ocupa un importante lugar con el 19\% y $11 \%$, que mantendrá hasta el fin de la década, el neofolklore se posiciona con un

75 Alabarces y Silba 2014.

76 Karmy, Ardito y Vargas 2011. 
consistente $11 \%$ y $10 \%$, para desaparecer después casi completamente. Luego, entre 1967 y 1970 el dominio de la canción melódica en sus versiones latinas y europeas es masivo.

\section{GRÁFICO 2}

\section{GÉNERO MUSICAL DE LAS CANCIONES, POR AÑO 1961-1970}

$(\mathrm{N}: 4.152)$

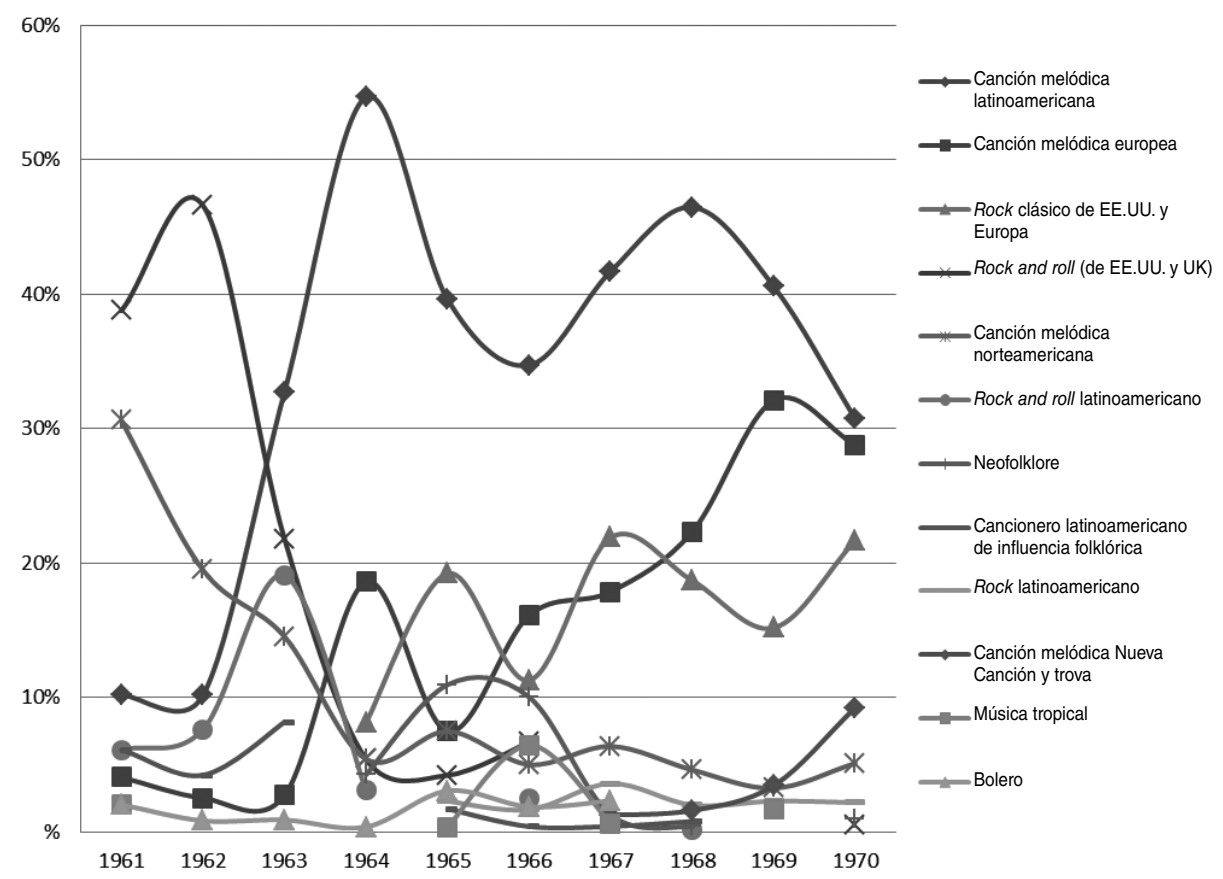

Fuente: Elaboración propia.

La segunda música juvenil son las versiones nacionales del rock and roll. Este género repuso el idioma castellano en las canciones y permitió construir un código juvenil propio, con el que la mayoría de los jóvenes podían identificarse: muy ligado a los ritmos de vida estudiantiles (la normatividad y sociabilidad escolar, las fiestas, las vacaciones) a las nuevas relaciones afectivas (el pololeo como ensayo del noviazgo) y mayoritariamente ritmos rápidos y sincopados, aunque se mantuvo la presencia de los lentos. Sus intérpretes eran jóvenes de apariencia de clase media, y aunque varios eran de origen popular, había una autoexclusión tácita de la clase alta ${ }^{77}$. Es posible agregar a esta música los intérpretes de la Nueva

77 La única cantante de origen acomodado presente en los rankings, Gloria Simonetti, fue abucheada en el Festival de Viña del Mar de 1968 porque se creía que usaba la influencia de su familia 
Ola que cantaban canciones melódicas, pero con una performance más informal, cercana a los rocanroleros.

Esta segunda corriente coexiste con la canción melódica europea, básicamente italiana y francesa. Códigos más accesibles que la música de EE.UU. por el idioma y el tono hicieron que tuviera notable presencia en el ranking y una importante influencia en los intérpretes melódicos nacionales de la Nueva Ola. Varios éxitos de esta corriente son covers de canciones juveniles italianas ${ }^{78}$.

Si examinamos las apariciones por año, estas variaciones se visibilizan (ver Gráfico 3). Paul Anka, Elvis Presley y los cantantes chilenos y argentinos de la Nueva Ola, que predominan hasta 1964, son reemplazados por The Beatles, que se mantienen hasta el final del período, y por Adamo, Raphael y Sandro a partir de ese mismo año. Hay varios chilenos con presencia importante hasta 1966, año en que son reemplazados por José Alfredo Fuentes.

GRÁFICO 3

FRECUENCIA DE APARICIÓN DE LOS INTÉRPRETES CON MAYOR PRESENCIA EN LOS RANKINGS JUVENILES, POR AÑO 1961-1970

$(\mathrm{N}: 1.450)$

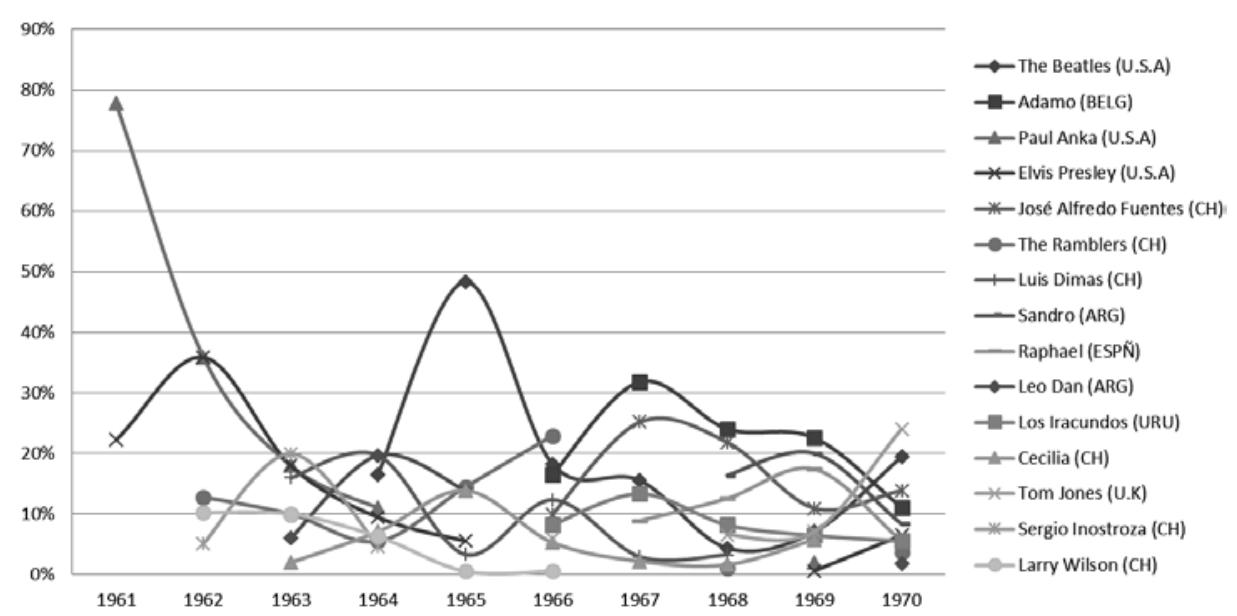

Fuente: Elaboración propia.

La tercera música juvenil se inicia con el desembarco de The Beatles en 1964, que se consolida con la película A Hard Day's Night. Con ellos se impusieron otros intérpretes de rock y pop anglo, incluso baladistas como Tom Jones. Tuvieron enorme influencia en los músicos locales, y dieron origen al rock nacional, pero en esta década su influencia se restringía a una elite, con pequeña presencia en

para favorecer su carrera (González, Ohlsen y Rolle 2009: 556).

78 González 2015. 
el ranking. El rol contestatario del rock fue asumido acá, como en España, por la Nueva Canción que fue excluida por razones políticas, pero con presencia sobre todo entre los jóvenes universitarios o militantes.

Con lo anterior, en la segunda mitad de la década las canciones sencillas de la Nueva Ola quedaron desplazadas por The Beatles. Junto a estos se instaló la "canción melódica"79 tanto en su versión europea (con Adamo, Raphael) como argentina (con Sandro, Yaco Monti, Leonardo Favio). En ese otro momento aparecieron cantantes melódicos nacionales que coexistieron con los extranjeros más populares. Presentados como Nueva Ola, lo eran sobre todo en función de su juventud, pero las canciones que interpretaban eran de género melódico (como fue el caso de José Alfredo Fuentes).

Un resultado interesante es que, lejos de la imagen de americanización, es hegemónica la presencia de intérpretes nacionales (39\%), y en segundo lugar, de estadounidenses (21\%). El restante se distribuye entre Argentina y Gran Bretaña, con una frecuencia de $9 \%$ cada uno, Italia con $5 \%$, y en los demás países $4 \%$ o menos (ver Gráfico 4). En consonancia con esto, el idioma de las canciones fue predominante la lengua castellana en más de $61 \%$, seguido con distancia del inglés $(34 \%)$. Otros idiomas como el francés o el italiano apenas superan el 2\%, mientras que el portugués, ruso, africano/inglés y el alemán, con frecuencias inferiores a $1 \%$, prácticamente son rarezas dentro del panorama musical de la década $^{80}$ (ver Gráfico 5).

GRÁFICO 4

PAÍS DE ORIGEN DE LOS INTÉRPRETES

$(\mathrm{N}: 4.076)$

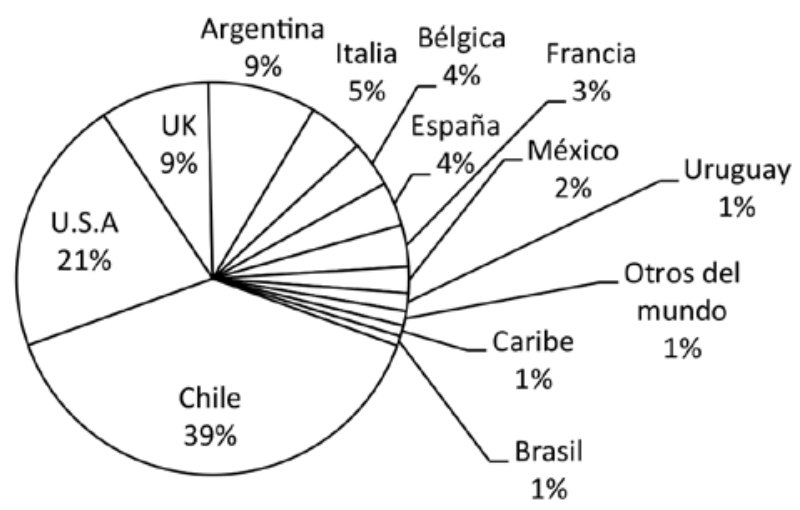

Fuente: Elaboración propia.

79 Pujol 2013.

80 Es posible señalar que hay un menor número de casos válidos por la presencia de piezas instrumentales (sin letra), no susceptibles de caracterizar. 
GRÁFICO 5

IDIOMA DE LAS CANCIONES

$(\mathrm{N}: 3.919)$

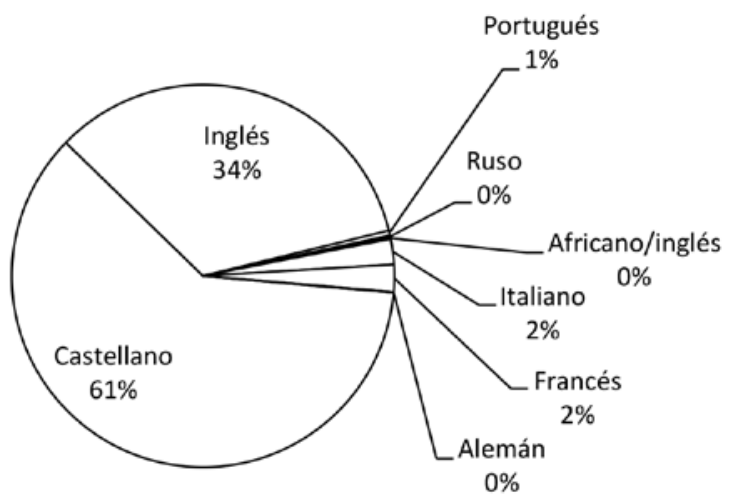

Fuente: Elaboración propia.

El idioma, al igual que los géneros, varía de acuerdo con los períodos. Según se observa en el Gráfico 6, a comienzos de los sesenta había predominio del inglés $(80 \%)$, reemplazado luego por el castellano de la Nueva Ola chilena y argentina, y por cantantes europeos que grababan en esta lengua para su público latinoamericano. Al siguiente año empieza a aparecer el italiano, que mantendrá una presencia minoritaria pero constante. Ya en 1963 se invierte la relación, siendo lo hispano lo predominante hasta 1970, con su peak en 1966 (75\%). También se escuchan obras en francés, portugués, africano/inglés y alemán, siempre en proporciones inferiores al $10 \%$.

GRÁFICO 6

IDIOMA DE LAS CANCIONES, POR AÑO 1961-1970

$(\mathrm{N}: 3.919)$

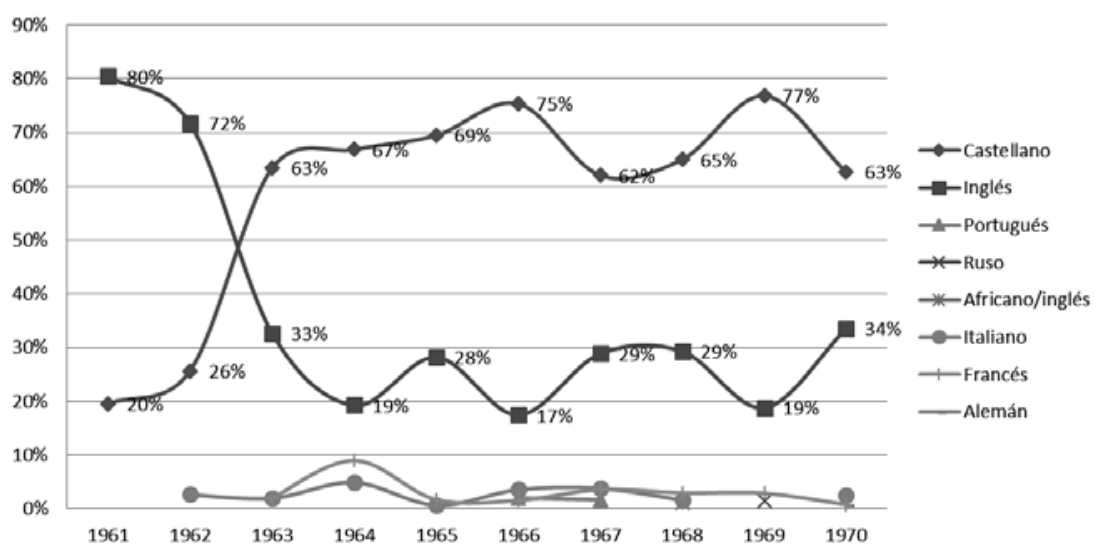

Fuente: Elaboración propia. 
El predominio del castellano se fortaleció porque franceses e italianos versionaban en castellano sus propios éxitos, retomando sus tradiciones, pero desde una perspectiva juvenil. Por ejemplo Salvatore Adamo, baladista que con ritmos adultos (valses, tangos y javas) y lazos evidentes con la "canción francesa" ${ }^{1}$ cantaba con gran sencillez y sentimentalidad los avatares amorosos de los jóvenes estudiantes y trabajadores belgas, lo bastante universales como para que al traducir al castellano sus canciones originalmente en francés, se adueñara del ranking por varios años.

Raphael tuvo un enorme éxito marcando una diferencia con los otros intérpretes juveniles del pop español, siendo una especie de puente entre las tradiciones musicales hispanas, latinoamericanas y de la canción francesa -la música adulta-, y la música juvenil, tanto en su repertorio, uso de la voz y performance $e^{82}$.

Joan Manuel Serrat, totalmente diferente, fue acogido con similar entusiasmo por la industria, dándole espacio en los medios y en los rankings. Desde el momento que empezó a grabar en castellano, el desconocido catalán de la Nueva Canço "se convirtió en un abrir y cerrar de ojos en el cantante-autor de consumo más importante del país. Sabía dialogar con la cotidianeidad y arrancarle un lenguaje común, a tono con la sentimentalidad de la gente más normal y corriente" 83 . Investido de la calidad de ídolo juvenil, encontramos a un Serrat crítico del ambiente represivo de la sociedad española franquista (y de paso de los convencionalismos de la sociedad chilena de los sesenta), más cercano a la Nueva Canción chilena, recibido por la industria nacional como uno de los suyos.

Los cantantes melódicos argentinos también tuvieron una gran presencia en los rankings. Sandro había partido como roquero y luego se recicló como baladista, pero desarrolló una performancey expresividad muy particular. Alabarces ${ }^{84}$ ha rescatado su otra identidad, al definirse no como europeo, sino gitano, no indio ni mestizo, sino que popular, con una corporalidad ostensible y erotizada, pero sin el salvajismo que se le adjudicaba al Elvis de los inicios, reemplazado por una presencia más acorde a la sensibilidad latina, que exageraba la emotividad por sobre la sensualidad ${ }^{85}$. Yaco Monti, también argentino y provinciano, llevó al extremo la emotividad de su interpretación, y desarrolló un sonido del que luego se apropiaron y desplegaron en Chile Los Ángeles Negros y Los Galos. Por su parte, Favio, cineasta devenido en cantante popular, se adueñó del ranking con una performance física más contenida que los anteriores, pero con la misma intensidad emocional y con letras de mayor nivel y audacia. Al igual que Serrat, Favio explicitaba que sus relaciones amorosas pasaban "la barrera de la intimidad", obligando a los administradores de los rankings a hacer la vista gorda.

Los cantantes europeos, de visible origen popular en sus propias sociedades, aparecían ante el público chileno desclasados y se transformaban en virtud de sus fenotipos blancos en aceptables como figuras de clase media. Lo mismo ocurría con los cantantes argentinos populares y provincianos, incluso de supuesto origen gitano,

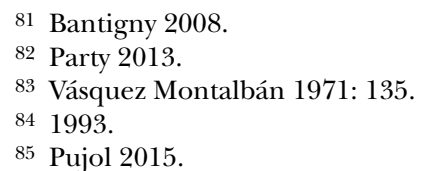


que mutaban en blancos, criollos, de cualquier forma, no indios. Esta reafirmación de lo europeo sobre lo mestizo y de lo clasemediero sobre lo popular también se imbrica con componentes de géneros. En cuanto a las diferencias entre hombres y mujeres, la mayoría de los intérpretes eran varones $(85 \%)$, siendo la proporción de mujeres muy menor en los rankings analizados $(13 \%)^{86}$. A esta escasa presencia femenina se suma que dentro de la Nueva Ola chilena "José Alfredo Fuentes desplazaba a Cecilia como ídolo, y con ello se cambiaba un modelo femenino transgresor por uno masculino obediente" 87 , mientras subterráneamente la Nueva Canción reconstruía una identidad popular más que mestiza.

\section{APROXIMACIONES FINALES}

Los resultados del análisis de los rankings permiten rechazar la tesis que en Chile, como en América Latina, la música responde a un proceso unidireccional de asimilación y adaptación estética a partir de una "importación o transferencia de sentido desde la centralidad europea hacia el margen colonial de la periferia" 88 , reduciendo la música popular al pop o al rock. Por el contrario, los resultados muestran una compleja combinación de influencias internacionales y nacionales entrecruzadas, reelaboradas y redirigidas, produciendo una mezcla de géneros musicales que se renueva mediante resistencias y asimilaciones.

La configuración de una particular música popular en Chile, la juvenil, responde al fenómeno de hibridación, es decir, a aquellos "procesos socioculturales en los que las estructuras o prácticas discretas, que existían en forma separada, se combinan para generar nuevas estructuras, objetos y prácticas" 89 . La hibridación es producida por las tecnologías avanzadas y los procesos sociales que van de la mano en el marco de la globalización y del surgimiento de las industrias culturales. La investigación permite afirmar, como García Canclini, que la hibridación en las urbes "dispone de una oferta simbólica heterogénea, renovada por una constante interacción de lo local con redes nacionales y trasnacionales de comunicación" 90 . En estos escenarios, es el mercado y la cultura local los que reordenan "el mundo público como escenario de consumo y dramatización de los signos de status" 91 e identidad. En este marco, la radio dentro de los medios de comunicación se vuelve constituyente y dominante del sentido -y del gusto- del público juvenil respecto de la música.

En la construcción de un gusto musical juvenil a partir del análisis de las listas de canciones elaboradas por revistas juveniles y del espectáculo operan varias tendencias: gran parte es lo que la misma industria nacional e internacional desea establecer como tal, pero también los gustos y las preferencias del público, expresadas en adquisiciones de discos y votación en las radios. Con ello, la misma noción de ranking instala la importancia de lo nuevo, la constante renovación del gusto que indica

\footnotetext{
86 El porcentaje restante correspondía a grupos mixtos.

87 González 2010: 30.

88 Osorio 2011: 2.

89 García Canclini 2005: 14.

90 García Canclini 2005: 260.

91 García Canclini 2005: 263.
} 
Bourdieu 92 , anhelo que presiona en el permanente cambio en los gustos, donde lo nuevo reemplaza lo que era éxito ayer. Es así como estas instituciones constituyen las grandes mediatizadoras y mediadoras de la vida cotidiana, promoviendo la creatividad y la innovación al alero de las nuevas tecnologías ${ }^{93}$.

Los datos aquí presentados también permiten afirmar que no estamos frente a una aceptación indiscriminada de los elementos de otras culturas -sobre todo del hemisferio norte en la década de los sesenta-, sino que la coexistencia específica de los géneros musicales se da de manera restringida, y a la vez heterónoma, coercitiva, concentrante de las iniciativas combinatorias en unas pocas sedes transnacionales de generación de mensajes y bienes, de edición y administración del sentido social ${ }^{94}$.

A ello se agrega la intencionalidad perceptible de parte de la industria de construir un gusto musical juvenil separado y diferente del mundo adulto, pero donde se busca difuminar, disfrazar y eludir las diferencias de clase. Se propone una construcción de identidad para este grupo social, que busca reconocerse en los códigos de la modernidad internacional donde los nuevos géneros musicales expresan a una juventud descontenta con las normas tradicionales de la sociedad adulta. Pero esos nuevos géneros tendrán una traducción nacional donde ese descontento es administrado y canalizado por la industria. Esta reconoce la necesidad de ofrecer a la juventud nuevos formatos (Nueva Ola, neofolklore) donde se rescaten y reposiciones elementos de identidad tradicional, como el ocultamiento de lo popular y mestizo en pro de una imagen blanqueada y de clase media que no sea disruptiva con el respeto a la autoridad. Precisamente, "nuestro país presenta procesos de conformación nacional construidos en categorías raciales donde lo blanco-europeo deviene un elemento central, tanto para definir simbólicamente a la nación como para afirmar la distinción entre clases sociales y posiciones de poder"95.

En la constitución de este nuevo habitus que reivindica lo joven como expresión privilegiada de lo humano, hay también una reivindicación de los gustos de las clases trabajadoras: en ropa, los jeans; en música, el rock and roll; y en modales, abandonando la formalidad de los buenos modales reemplazándolos por la espontaneidad ${ }^{96}$. En los intérpretes, tanto varones como mujeres, existe apropiación de estos cambios culturales y se va instalando una identidad juvenil más libre e irresponsable que la de los adultos ${ }^{97}$.

Por último, es factible señalar que los rankings de música son construidos por actores interesados de la industria, por lo que solo reflejan parcialmente la música más transmitida y escuchada en las radios. Los rankings en prensa empleados para este estudio concerniente a música popular y jóvenes en los años sesenta en Chile también constituyen "una definición específica de lo que debe ser computado como música popular". Precisamente, "las listas proporcionan discos seleccionados conjuntamente en el seno de la comunidad del mercado, definen de un modo muy específico ciertos tipos de consumo como afirmación colectiva" 98 . En ese sentido, las

\footnotetext{
92 1979/1998; 2003/2010.

93 García Canclini 2005.

94 García Canclini 2005.

95 Tijoux 2013: 289-290.

96 Hobsbawm 1999.

97 Lamadrid 2014.

98 Frith 2001: 419.
} 
listas constituyen una fuente plausible acerca de la popularidad "que se usan siempre para crear (más que reflejar) comunidades reunidas en torno a unos mismos gustos"99. Pese a la limitación anterior, se plantea la necesidad de seguir estudiando los géneros musicales y la construcción de identidades, como una fuente inagotable para indagar y comprender ciertos momentos sociohistóricos, donde confluyen las fuerzas de producción y difusión cambiantes, siempre en contextos más amplios de significación social.

\section{BIBLIOGRAFÍA}

Alabarces, Pablo

1993 Entre gatos y violadores: el rock nacional en la cultura argentina. Buenos Aires: Ediciones Colihue.

Alabarces, Pablo y Malvina Silba

2014 "Las manos de todos los negros, arriba: Género, etnia y clase en la cumbia argentina", Cultura y representaciones sociales, 8/16 (marzo), pp. 52-74.

Asún, Rodrigo

2006 "Medir la realidad social. El sentido de la metodología cuantitativa", Metodologías de la Investigación Social. Introducción a los oficios. Editado por Manuel Canales. Santiago de Chile: Editorial LOM, pp. 31-61.

BANTIGNy, Ludivine

2008 "Les deux écoles. Culture scolaire, culture de jeunes: genèse et troubles d'une rencontre, 1960-1980", Revue française de pédagogie. Recherches en éducation, $\mathrm{N}^{\circ} 163$ (abril-junio), pp. 15-25.

BennetT, ANDy

2000 Popular music and youth culture: music, identity and place. New York: Palgrave Macmillan Press Ltd.

BIANCHI, SOLEDAD

1987 "Música, noticias, alegría, no cambie el dial", Cahiers du monde hispanique et lusobrésilien, 48/1, pp. 149-153.

Bourdieu, PiERre

1979/1998 La distinción. Criterio y bases sociales del gusto. Madrid: Grupo Santillana de Ediciones S.A.

2003/2010 El sentido social del gusto. Elementos para una sociología de la cultura. Buenos Aires: Siglo XXI Editores.

Brabazon, TARA

1993 "Beatlemania, Beatle photographs and a female gaze". Sexuality and gender in history: selected essays. Editado por Penelope Hetherington y Philippa Maddern. Nedland, Australia: University of Western Australia, pp. 21-44.

Cea D’Ancona, María de los Ángeles

1998 Metodología cuantitativa: estrategias y técnicas de investigación social. Madrid: Editorial Síntesis.

${ }^{99}$ Frith 2001: 419. 
Duarte, Klaudio

2000 "Juventud o juventudes? Acerca de cómo mirar y remirar a las juventudes en nuestro continente", Última Década, 13 (septiembre), pp. 59-77.

Estrada, Tere

2008 Sirenas al ataque. Historia de las mujeres rockeras mexicanas. México: Editorial Océano.

FriTh, SimON

2001 "Hacia una estética de la música popular", Las culturas musicales. Lecturas de etnomusicología. Editado por Francisco Cruces. Madrid: Editorial Trotta, pp. 413-435.

García Canclini, Néstor

2005 Culturas híbridas. Estrategias para entrary salir de la modernidad. Buenos Aires: Editorial Paidós.

Garibaldo, Ramón y Mario Bahena

2015 "El ruido y la nación: cómo el rock iberoamericano redefinió el sentido de comunidad en Latino América”, Diálogos Revista Electrónica de Historia, 16/1 (enero-junio), pp. 191-214.

Giménez, GiLberto

1999 "La investigación cultural en México: una aproximación", Perfiles latinoamericanos: revista de la Facultad Latinoamericana de Ciencias Sociales (México), 15 (enero-junio), pp. 119-138.

González, Juan Pablo

2001 "Musicología popular en América Latina: síntesis de sus logros, problemas y desafíos", Revista musical chilena, LV/195 (enero-junio), pp. 38-64.

2006 "Rock, memoria del cuerpo". Cátedra de Artes, 3 (segundo semestre), pp. 9-24.

2010 "La mujer sube a la escena: Estrellas de la canción en el Chile del sesquicentenario”, NEUMA Revista de Música y Docencia Musical, 3/3, pp. 10-33.

2015 "Postwar Italian popular music and the New World", Italian Migration and Urban Music Culture in Latin America. Editado por Nils Grosch y Rolf Kailuweit Münster. New York: Waxman.

González, Juan Pablo, Oscar Ohlsen y Claudio Rolle

2009 Historia Social de la Música Popular en Chile, 1950-1970. Santiago de Chile: Ediciones Universidad Católica de Chile.

GonZÁlez, YANKo

2011 "Primeras culturas juveniles en Chile: Pánico, malones, pololeo y matiné", Atenea, 503, pp. 11-38.

Guerrero, Juliana

2012 "El género musical en la música popular: algunos problemas para su caracterización”. TRANS-Revista Transcultural de Música/Transcultural Music Review, 16 [Fecha de consulta: 12/02/17]

Gutiérrez, Matías

2005 "El nuevo folklore argentino de los ‘50, sus influjos y comentarios críticos. Hipótesis sobre su circulación social". Disponible en: http://www.catedras.fsoc.uba.ar/ steimberg/pdf/gutierrezr01.pdf

Hernández, Roberto, Carlos Fernández y Pilar Baptista

2010 Metodología de la Investigación. Quinta Edición. México: McGraw-Hill. 
Hobsbawm, Eric

1999 Historia del Siglo XX. Buenos Aires: Editorial Grijalbo Mondadori.

Hormigos, Jaime y Antonio Martín Cabello

2004 "La construcción de la identidad juvenil a través de la música", Revista Española de Sociología, 4, pp. 259-270.

Karmy, Eileen, Lorena Ardito y Alejandra Vargas

2011. "Tiesos pero cumbiancheros: perspectivas y paradojas de la cumbia chilena", ¿Popular, pop, populachera? El dilema de las músicas populares en América Latina. Actas del IX Congreso de la IASPM-AL. Editado por Carolina Santamaría, Heloísa de Araujo, Herom Vargas y Óscar Hernández. Montevideo: IASPM-AL y EUM, pp. 398-411

Kouvarou, María

2015 "American Rock with a European Twist: The Institutionalization of Rock'n'Roll in France, West Germany, Greece, and Italy (20th Century)", Historia Crítica, 57, pp. 75-94.

LAMADRID, Silvia

2014 Ritmo revisitado. Representaciones de género en los 60. Santiago de Chile: Editorial Cuarto Propio.

LARRAÍN, JORGE

2004 Identidad y modernidad en América Latina. Ciudad de México: Editorial Océano de México.

Malacara, Antonio

2001 Catálogo Subjetivo y Segregacionista del Rock Mexicano. México: Editorial CONACULTA/ FONCA.

MARTín, EnRIQUe

1998. Producir la juventud: crítica a la sociología de la juventud. Tres Cantos, España: Editorial Istmo.

Mularski, JeDreK

2015 "Singing Huasos: Politics, Chilenidad, and Musicfrom 1910-1950", A Contracorriente, 12/2, pp. 178-211.

Muñoz-Hidalgo, Mariano

2007 "Bolero y Modernismo: La canción como literatura popular", Literatura y Lingüística, 18, pp. 101-120.

ORdovÁs, JEsús

1986 Historia de la música pop española. Madrid: Alianza Editorial.

OSORIO, JAVIER

2011 "Rock, dependencia y apropiación. Los Beat 4 y la crítica a la imitación en los años sesenta”, Ponencia del Primer Congreso Chileno de Estudios en Música Popular. En VV.AA. ¿Qué hay de popular en la música popular? Actas del Primer Congreso Chileno de Estudios en Música Popular. Santiago de Chile: ASEMCH y Universidad Alberto Hurtado. Junio de 2011.

Otaola, Paloma

2012 "La música pop en la España franquista: rock, ye-ye y beat en la primera mitad de los años 60", ILCEA, 16, pp. 1-13. 


\section{Palominos, Simón}

2011 "Explorando las culturas populares: algunos elementos sociohistóricos para el estudio", Ponencia del $6^{\circ}$ Congreso de Sociología y Encuentro PRE-ALAS, Santiago de Chile. 15 de abril. Grupo de Trabajo No 32: Sociología del Arte y la Cultura, pp. 1-16.

Party, Daniel

2013 "Raphael is different: Spanish 'canción melódica' under late Francoism”, Music and Francoism. Editado por Gemma Pérez Zalduondo and Germán Gan Quesada. Turnhout: Brepols Publishers, pp. 285-300.

\section{Polimeni, Carlos}

2001 Bailando sobre los escombros: historia critica del rock latinoamericano. Buenos Aires: Editorial BIBLOS.

Pujol, Sergio

2013 "Tango y universo juvenil: breve historia de una reconciliación”, Artcultura, 14/24, pp. 9-18.

2015 "Escúchame, alúmbrame. Apuntes sobre el canon de "la música joven" argentina entre 1966 y 1973”. Apuntes de investigación del CECYP 2015. Año XVII. No 25. pp. 11-25. Disponible en: http://www.apuntescecyp.com.ar/index.php/apuntes/ article/view/526/409.

Salazar, Gabriel y Julio Pinto

2002 Historia Contemporánea de Chile. Tomo V. Niñez y Juventud. Santiago de Chile: Editorial LOM.

Santamaría Delgado, Carolina

2005. "De la generalidad de lo genérico al género: la industria musical y la producción de identidades latinoamericanas en la primera mitad del siglo XX". Ponencia publicada en Actas del VI Congreso Latinoamericano IASPM-AL, Buenos Aires.

SOLÍS, VALERIA

2010 Suena desafinado. Tomando el pulso a la industria de la música en Chile. Santiago de Chile: Sin editorial.

Tijoux, María Emilia

2013 "Las escuelas de la inmigración en la ciudad de Santiago: Elementos para una educación contra el racismo", Polis, 12/35, pp. 287-307.

VALDÉz, MERCED

2001 Ahí la Llevamos Cantinfleando. México. Edición de autor.

Vázouez Montalbán, Manuel

1971 Crónica sentimental de España. Barcelona: Editorial Lumen.

VEGA, HÉctor

2011 "La música tradicional mexicana: entre el folclore, la tradición y la Worldmusic", Historia Actual Online, 23, pp. 155-169.

Vila, PABlo

1987 "Tango, folklore y rock: apuntes sobre música, política y sociedad en Argentina", Cahiers du monde hispanique et luso-brésilien, 48/1, pp. 81-93. 